\title{
Modalidade semipresencial de ensino: alguns resultados da implantação em disciplinas de graduação da UPF
}

\author{
Ana Carolina Bertoletti De Marchi - UPF Virtual/UPF - carolina@upf.br \\ Daniela De David Araújo - UPF Virtual/UPF - david@upf.br \\ Isléia Rossler Istreit - UPF Virtual/UPF - istreit@upf.br
}

Resumo. A semipresencialidade é uma modalidade de ensino reconhecida no Brasil e regulamentada desde 2004. Tal metodologia é considerada pertinente e adequada para aproximar o estudante de cursos superiores das novas Tecnologias de Informação e Comunicação (TICs), bem como para difundir entre o corpo docente aspectos pertinentes à Educação a Distância $(\mathrm{EaD})$. Todavia, por se tratar de uma proposta ainda recente no ensino superior, análises de sua aplicabilidade são pouco difundidas. Neste sentido, o artigo apresenta a descrição dos resultados obtidos com o processo avaliativo da primeira disciplina semipresencial ministrada em um curso de graduação da Universidade de Passo Fundo (UPF), aplicado ao professor e aos alunos. Como resultados quantitativos desta primeira experiência apresentam-se: a) a criação de modelos de semipresencialidade; b) o desenvolvimento de um guia de orientações; c) a aprovação de Diretrizes Institucionais, com vistas à ampliação dessa modalidade na instituição; d) a reformulação da formação docente em EaD na instituição.

Palavras-chave: semipresencialidade, educação a distância e formação docente.

Semipresential teaching: some results of the implantation of that modality in the graduation courses of the University of Passo Fundo

Abstract. The semipresential teaching is an educational modality which has been legally recognized in Brazil since 2004. Such methodology is considered pertinent to move the academic toward the Information and Communication Technologies, as well as to propagate among professors some aspects related to Distance Learning. However, once it still is a recent proposal in higher education, there are not many analyses of its applicability available. This paper presents the description of the results obtained during the process of evaluation of the first semipresential subject developed at the University of Passo Fundo, applied to the professor and also to the academics. As qualitative results, it is possible to highlight: a) the establishment of models to the semipresential subjects; $b$ ) the development of an orientation guide; $c$ ) the approval of Institutional Guidelines, aiming at the enlargement of that modality in the institution; $d$ ) the reformulation of the training courses offered to the professors.

Keywords: semipresential teaching, distance learning and training courses.

\section{Introdução}

Em 2004, através da Portaria 4.059, o Ministério da Educação autorizou a implementação da semipresencialidade nos cursos de graduação reconhecidos das instituições de ensino superior. Os cursos de graduação que desejam ofertar disciplinas na modalidade semipresencial devem regulamentá-las nos projetos pedagógicos, 
respeitando o limite de $20 \%$ (vinte por cento) da carga horária prevista para a integralização curricular.

Com base na legislação vigente, o setor responsável pelas ações de Educação a Distância (EaD) na Universidade de Passo Fundo (UPF), denominado Divisão UPF Virtual, compreende a semipresencialidade como uma modalidade de ensino que possibilita a incorporação de atividades não-presenciais, bem como de técnicas e metodologias de $\mathrm{EaD}$, ao programa das disciplinas que integram a matriz curricular dos cursos de graduação.

A Universidade de Passo Fundo acredita que tal alternativa vem ao encontro dos interesses e das necessidades dos cursos, uma vez que a utilização de métodos e de ferramentas vinculadas à educação a distância possibilita aos acadêmicos a aproximação e a apropriação no uso das tecnologias de informação e comunicação. Além disso, qualifica a formação profissional por incentivar o espírito de investigação, a interação e a colaboração nas relações acadêmicas e na construção do conhecimento. Dessa forma, a modalidade semipresencial é uma proposta em expansão na UPF, que reflete uma tendência educacional nas instituições de ensino superior do país e uma aposta na ampliação das possibilidades de interação no fazer pedagógico.

Diante deste contexto, em 2007, a UPF ofertou a primeira disciplina semipresencial no curso de Secretariado Executivo Bilíngüe. Os resultados obtidos a partir da avaliação dos alunos e do professor que ministrou a disciplina são apresentados neste artigo. Para tanto, também são abordadas algumas questões inerentes à educação a distância e à proposta da UPF para difundir a semipresencialidade nos cursos de graduação reconhecidos.

\section{Princípios básicos adotados para a semipresencialidade}

A opção pelo envolvimento com atividades de EaD na Universidade de Passo Fundo, após sua trajetória de 40 anos em cursos totalmente presenciais, vem sendo paulatinamente construída junto à comunidade acadêmica. Pauta-se, para tanto, pela legislação específica em vigor e, ainda, pela normatização estabelecida internamente, sob coordenação da Divisão UPF Virtual.

$\mathrm{Na}$ modalidade semipresencial, estudantes e professores estão separados fisicamente em determinados momentos da disciplina, mas interligados por meio das tecnologias de comunicação e interação e dos materiais didáticos empregados. Por tais especificidades, a semipresencialidade torna-se um elemento a mais de flexibilização curricular, no que diz respeito às condições individuais de cada estudante, ao ritmo de aprendizagem, ao local e ao tempo de dedicação aos estudos.

$\mathrm{Na}$ UPF, a semipresencialidade vem se consolidando, passo a passo, como uma alternativa pedagógica, comprometida com o processo de formação humana, com a construção e com a sociabilização do conhecimento. Considera-se tal modalidade uma nova oportunidade para cumprir a missão institucional, ampliando a atuação da UPF na comunidade regional, produzindo e difundindo conhecimentos que promovam a melhoria da qualidade de vida e a formação de cidadãos competentes, com postura crítica e autônoma diante dos desafios que cercam a sociedade contemporânea, de modo a atuarem como agentes de transformação.

A responsabilidade agregada às atividades não-presenciais para o cumprimento da missão institucional está fundamentada, especialmente, em seis princípios que fazem 
desta modalidade de ensino uma opção significativa para a formação de profissionais comprometidos (SEAD/MEC 2007), (Maia e Mattar 2007), (Moore e Kearsley 2007) e (Filatro 2007). São eles:

- interação e aprendizado colaborativo: permite a construção do conhecimento pelo viés do diálogo e da troca constante de saberes junto aos colegas e professores, que superam a distância física e temporal nas relações interpessoais, tendo em vista o compromisso assumido com o desenvolvimento intelectual, cultural e humano dos sujeitos envolvidos no processo educativo;

- autonomia na aprendizagem: contribui para a formação de um sujeito comprometido com o estudo, responsável pela organização de seu tempo na busca contínua do aprender. $\mathrm{O}$ aluno deve assumir sua autonomia, envolvendo-se numa rede de relacionamentos que favoreça o desenvolvimento cognitivo de todo o grupo;

- flexibilização do tempo e do espaço: possibilita a realização das atividades da disciplina em horário e local mais apropriado ao acadêmico, em especial àquele já inserido no mercado de trabalho, reduzindo as horas de deslocamento até a universidade e possibilitando o cumprimento das atividades, de acordo com a necessidade e característica de cada aluno;

- potencialização das ferramentas tecnológicas na educação: considera as Tecnologias de Informação e Comunicação a serviço do processo de ensinar e aprender à distância, fomentando a apropriação das mesmas em prol da formação humana e profissional, uma vez que o aluno incorpora tal instrumental ao seu cotidiano em busca do cumprimento dos objetivos da disciplina;

- qualidade dos materiais e da metodologia: prevê um processo cuidadoso nas fases de planejamento, desenvolvimento, implantação e avaliação dos materiais a serem adotados nas disciplinas ou unidades curriculares, considerando, ainda, a realidade dos acadêmicos e o atendimento de suas necessidades;

- apoio e suporte: mantém estrutura de apoio técnico e pedagógico ao acadêmico, objetivando a interação permanente com o estudante, o esclarecimento de suas dúvidas e o incentivo para a continuidade dos estudos, de forma a fortalecer o engajamento do aluno com o curso.

\section{A semipresencialidade no curso de Secretariado Executivo Bilíngüe}

O bacharelado de Secretariado Executivo Bilíngüe tem duração de seis semestres e é reconhecido pelo Ministério da Educação através da Portaria 951, de 22 de junho de 1999. O currículo é focado nas competências profissionais, enfatizando aspectos da gestão e da formação humanística. Os egressos são profissionais aptos a atuar junto aos dirigentes de organizações públicas e privadas, na função de assessoria, podendo também trabalhar de forma autônoma e polivalente, em um cenário de grandes e rápidas mudanças.

A reforma curricular realizada no segundo semestre de 2006 introduziu, entre outras inovações, a semipresencialidade nas disciplinas Língua Portuguesa II e Língua Portuguesa III. Cada disciplina totaliza 60 horas/aula e é desenvolvida, respectivamente, no segundo e quarto semestre do curso, com oferta inicial prevista para o primeiro semestre letivo de 2007. 
Ressalta-se, ainda, que o docente responsável pela condução das disciplinas semipresenciais, integrante do colegiado de professores do curso, tem experiência em educação a distância, com pós-graduação concluída na área.

\section{Material didático e mídias de interação e comunicação utilizadas nas disciplinas semipresenciais}

Construídos pelos professores em parceria com a equipe da Divisão UPF Virtual, o material didático utilizado nas disciplinas semipresenciais tem papel fundamental para o bom andamento das atividades à distância. Sua elaboração cuidadosa é condição para potencializar a comunicação entre os sujeitos afastados fisicamente. Construir um material didático dialógico, que apresente os conteúdos de forma clara e objetiva, é um dos desafios a ser enfrentado nesta modalidade de ensino.

$\mathrm{Na}$ UPF, o fluxo de produção do material didático observa o esquema ilustrado na Figura 1. A seta pontilhada que segue do aluno ao professor representa os resultados de avaliação, considerados para a atualização e para a revisão do material.

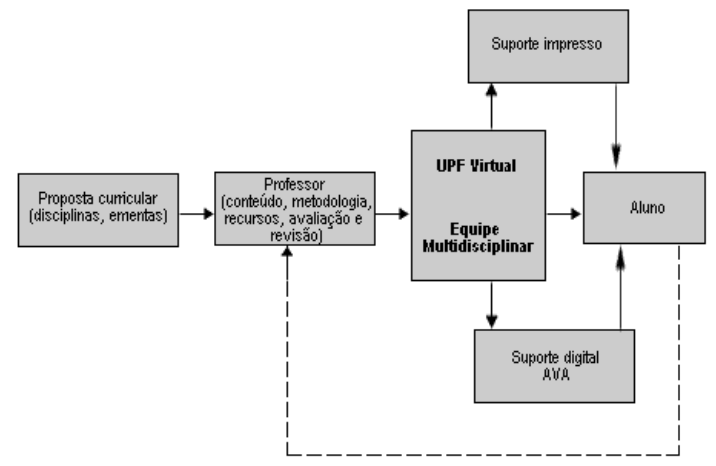

Figura 1 - Fluxo de produção do material didático

No que se refere à organização do material didático, faz-se necessário definir as estratégias didáticas, a linguagem e as mídias a serem utilizadas. Dentre as principais preocupações dos professores envolvidos nas disciplinas semipresenciais estão as que seguem: a) o que dizem os referenciais de qualidade do MEC a respeito dos materiais didáticos para momentos não-presenciais? b) que elementos devem ser considerados na organização da disciplina semipresencial e na elaboração dos materiais a serem apresentados aos alunos? c) como organizar o conteúdo da disciplina a partir das mídias escolhidas? d) que linguagem utilizar na produção dos textos que orientam os alunos ao estudo? e) que atividades solicitar aos acadêmicos? f) como promover a troca constante, o trabalho colaborativo e a discussão dos temas pertinentes à disciplina? g) como garantir a qualidade?

Tais questionamentos estão vinculados ao design instrucional, que, segundo Filatro (2007), refere-se ao processo pelo qual o professor, o designer instrucional ou uma equipe de profissionais se depara ao preparar e planejar o ensino. Dentre as fases que devem ser seguidas neste processo, a estruturação do conteúdo assume importância por considera as características/condições do público-alvo, os objetivos, as estratégias e os instrumentos de avaliação da disciplina semipresencial. Para tanto, pode-se adaptar materiais já existentes, elaborar textos 
próprios, além de selecionar outras mídias para incorporar estratégias educacionais diversificadas e condizentes com as atividades que serão solicitadas aos alunos. A Figura 2 ilustra alguns dos principais aspectos a serem considerados durante o processo.

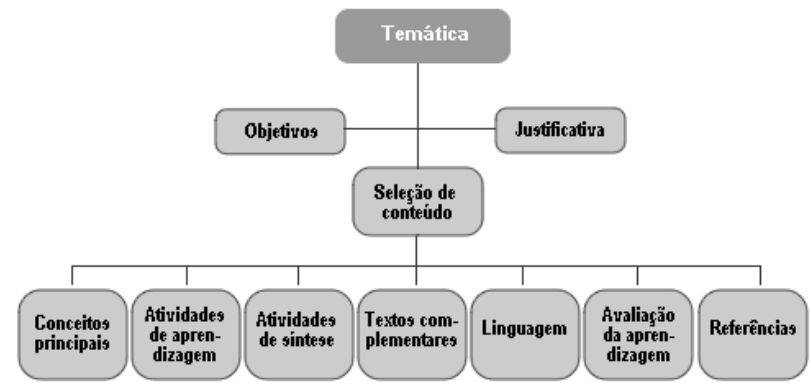

Figura 2 - Estrutura de organização dos materiais didáticos

Para mediar a relação entre os sujeitos envolvidos nas disciplinas semipresenciais, a UPF conta, inicialmente, com cinco frentes de interações, a seguir discriminadas:

- Ambiente Virtual de Aprendizagem (AVA): é configurado como o principal espaço social de interações entre estudantes e professores do curso, onde todos os sujeitos envolvidos poderão dialogar, trocar idéias, compartilhar conhecimentos, cooperar. O AVA caracteriza-se pela existência de estratégias e de intervenções que levam os estudantes a construir e a se transformar juntos, tornando-os produtores de informações. Nesse sentido, o AVA apresenta ferramentas que potencializam os processos de interação, de colaboração e de cooperação. Torna-se, portanto, um canal de comunicação direto entre os sujeitos da disciplina semipresencial.

- Vídeo-aulas: ferramenta pedagógica veiculada através do ambiente virtual de aprendizagem, produzida pela Divisão UPF Virtual.

- Videoconferência: tecnologia utilizada para a transmissão dos encontros presenciais, fazendo com que o professor e os alunos vejam e sejam vistos dentro da estrutura multicampi da universidade.

- Meios de comunicação em geral: serviço oferecido com o propósito de dar suporte aos estudantes no que se refere ao ambiente de apoio virtual ou, até mesmo, às questões mais diretamente relacionadas às disciplinas. Para isso, através da estrutura da universidade e da Divisão UPF Virtual, são utilizados fax, telefone e meios de comunicação computacionais (como e-mail e conversação síncrona) para contatar os alunos sempre que necessário.

- Ambiente de apoio ao Ensino: através do número de matrícula, cada aluno tem acesso à intranet da UPF, podendo usufruir de serviços (agenda, cotas de impressão, consulta ao sistema acadêmico para verificação de notas, frequiência, entre outros) e, ainda, acompanhar as notícias e informações institucionais.

$\mathrm{Na}$ disciplina semipresencial de Língua Portuguesa II, objeto deste relato de experiência, os principais meios de comunicação utilizados foram: a) ambiente virtual de aprendizagem; b) meios de comunicação em geral; c) ambiente de apoio ao ensino. Com isso, procura-se contemplar os três tipos distintos de interação citados por Moore e Kearsley (2007): (i) interação aluno x conteúdo; (ii) interação aluno x professor; (iii) interação aluno x aluno. 


\section{Resultados da primeira experiência}

A avaliação de uma disciplina semipresencial tem o objetivo de analisar resultados com vistas ao desenvolvimento e à melhoria na qualidade em suas diferentes dimensões. A operacionalização de sistematizações e análises possibilita a identificação de fragilidades e potencialidades de forma a emitir juízo de valor acerca da qualidade da disciplina semipresencial, objetivo último de qualquer processo avaliativo.

Neste sentido, a aplicação de um instrumento avaliativo visa buscar indícios que venham a comprovar a eficiência da metodologia proposta; também serve como ponto de partida para eventuais aprimoramentos e novas frentes de trabalho. Cabe ressaltar que o instrumento apresentado não foi a única fonte de avaliação empregada. Os alunos também foram convidados a responder o questionário online de avaliação aplicado semestralmente pela Comissão Própria de Avaliação da UPF.

$\mathrm{O}$ instrumento avaliativo, especialmente elaborado para a disciplina semipresencial, é composto por 25 questões que são divididas em 5 categorias, a seguir identificadas:

1.como aluno, você (questões de 2 a 7): visa identificar o grau de satisfação do aluno com relação à disciplina semipresencial no que se refere aos conhecimentos básicos necessários; à iniciativa em procurar o professor etc;

2.quanto ao professor (questões de 8 a 13): procura avaliar o professor quanto à linguagem utilizada e às atividades propostas;

3.quanto às práticas didático-pedagógicas adotadas (questões de 14 a 19): possibilita ao aluno verificar se os objetivos da disciplina foram atendidos; se o conteúdo conseguiu ser compreendido; se foram oportunizadas interações entre os colegas; se foram utilizados diferentes recursos etc;

4.quanto ao ambiente virtual de aprendizagem (questões 20 e 21): procura identificar se o ambiente atende às necessidades da disciplina e se é de fácil navegação;

5.quanto ao trabalho da UPF Virtual (questões 22 e 23): busca avaliar se o setor soluciona as dificuldades no uso do ambiente virtual e se possui infraestrutura necessária para o acompanhamento das atividades nãopresenciais.

Das 25 questões, 23 são objetivas e 2 descritivas. Para o preenchimento das perguntas objetivas, os alunos deveriam assinalar, no local apropriado, entre as alternativas de 1 a 5 , a que melhor expressasse sua opinião, sendo 5 a de maior nota". A Tabela 1 ilustra um exemplo de questão da categoria "Quanto ao professor".

Tabela 1 - Exemplo de questão da categoria "Quanto ao professor"

\begin{tabular}{|c|c|c|c|c|c|}
\hline Questão & 1 & 2 & 3 & 4 & 5 \\
\hline $\begin{array}{l}\text { Quanto ao professor, propõe atividades que valorizam a reflexão e proporcionam a } \\
\text { cooperação entre os alunos? }\end{array}$ & & & & & \\
\hline
\end{tabular}

\footnotetext{
${ }^{1}$ Apresenta-se a legenda que identifica os conceitos utilizados na avaliação: 1 - discordo totalmente; 2 discordo em partes; 3 - não concordo, nem discordo; 4 - concordo em partes; 5 - concordo totalmente.
} 
O questionário foi respondido por 46 alunos pertencentes às duas turmas da disciplina Língua Portuguesa II do curso de Secretariado Executivo Bilíngüe. Registra-se que, na época, foram desenvolvidas no campus Passo Fundo e no campus Soledade. É importante salientar que o mesmo professor ministrou as duas disciplinas, sendo que tiveram um alto grau de semipresencialidade: $80 \%$ da cargahorária, ou seja, dos 16 encontros previstos no cronograma da disciplina para o semestre 2007/1, 12 foram desenvolvidos à distância.

A média das questões por categoria pode ser visualizada no gráfico da Figura 3, onde também é possível identificar que a categoria de maior nota foi a de número 4 (Quanto ao ambiente virtual de aprendizagem), demonstrando que as ferramentas estavam adequadas à prática didático-pedagógica. Todavia, os alunos encontraram dificuldades no acesso à internet, pelo fato de que muitos residem em cidades pequenas e com infra-estrutura precária para ambientes que disponibilizam diversas mídias. Sobre esse aspecto específico, registra-se que, do total de alunos respondentes, $50 \%$ acessaram o ambiente virtual de aprendizagem para o acompanhamento da disciplina no local de trabalho. Os demais mencionaram que o acesso à internet foi possível por meio dos laboratórios de informática da instituição ou de suas residências.

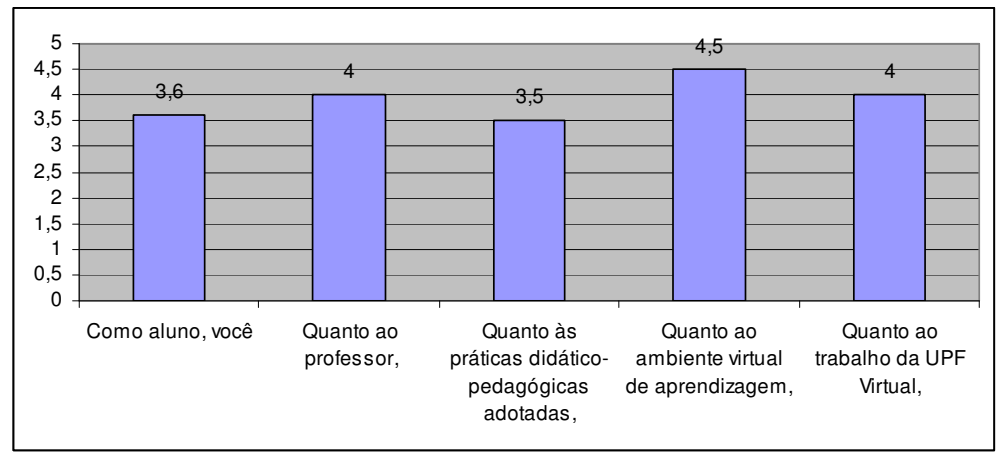

Figura 3 - Gráfico com a média geral por categoria

As médias individuais das questões estão expressas na Figura 4. Conforme o gráfico, as questões que obtiverem maior média, considerando cada categoria foram:

- questão 2. "Como aluno, você considera que seus conhecimentos de informática foram suficientes para o acompanhamento da disciplina semipresencial?", com 4,5;

- questão 13. "Quanto ao professor, oferece a possibilidade de refazer trabalhos?", com 4,9;

- questão 19. "Quanto às práticas didático-pedagógicas adotadas, são adequadas em relação ao tempo destinado para a realização de cada atividade?", com 3,8;

- questão 21. "Quanto ao ambiente virtual de aprendizagem, é de fácil navegação?", com 4,7;

- questão 23. "Quanto ao trabalho da UPF Virtual, possui infra-estrutura necessária para o acompanhamento das atividades não-presenciais?”, com 4,1 . 
Por sua vez, as questões com menor média são:

- questão 4. "Como aluno, você procura a UPF Virtual quando está com dificuldades no conteúdo ou na utilização do Ambiente Virtual?", com 2,9;

- questão 16. "Quanto às práticas didático-pedagógicas adotadas, estão adequadas em relação ao número de encontros presenciais e nãopresenciais?", com 3,2 .

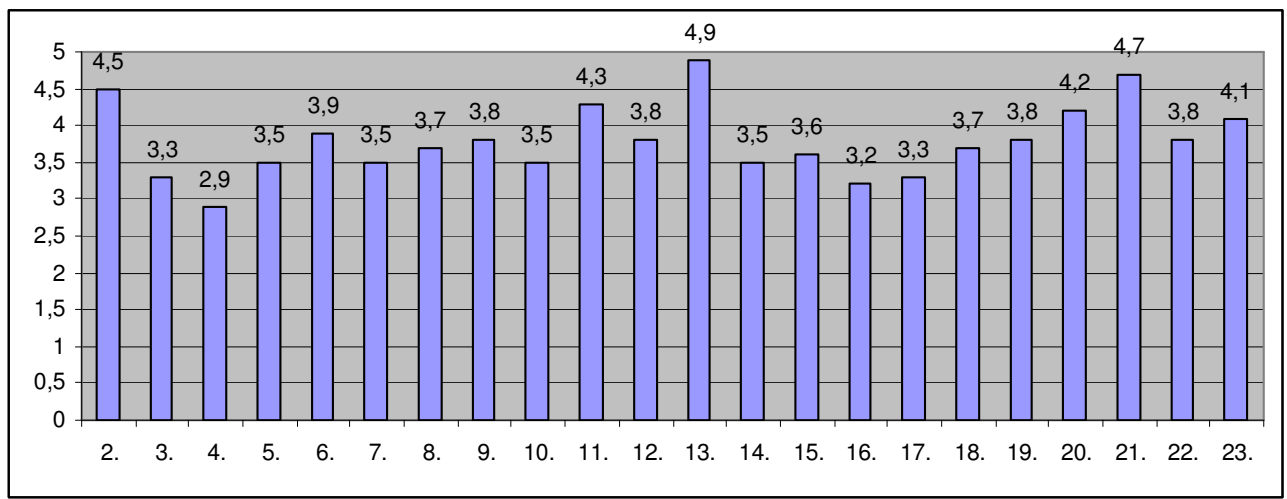

Figura 4 - Gráfico com a média individual das questões

Como pontos positivos, os alunos destacaram que a disciplina semipresencial estimula o esforço pessoal e a autonomia do aluno; possibilita a ampliação e o emprego dos conhecimentos de informática; desenvolve a auto-organização do estudante; possibilita a flexibilização do espaço e do tempo para o cumprimento das atividades solicitadas; permite que o professor acompanhe e oriente o aluno de forma continuada, se comparada à disciplina totalmente presencial. Os pontos negativos foram, principalmente, a dificuldade de acesso à internet; a pouca habilidade no uso das ferramentas básicas de informática para a navegação e realização das tarefas no ambiente virtual de aprendizagem.

Quanto à avaliação do professor, cabe destacar, dentre os aspectos negativos, a falta de conhecimento básico dos alunos em informática (tais como: configuração de documento; envio e recebimento de arquivo anexo em correio eletrônico; uso diferentes versões de software etc). Tais aspectos são decorrentes, segundo o professor, das condições sócio-econômicas da maioria dos alunos, que não conseguem ter um computador, com acesso à internet, para uso doméstico. Dentre os aspectos positivos estão, ao final da disciplina, a superação das dificuldades citadas acima e o desenvolvimento da postura de alunos mais ousados, interessados e dedicados, pois adotaram uma atitude ativa na construção do conhecimento.

\section{Proposta de expansão e organização das disciplinas semipresenciais}

Tendo por base a análise dos primeiros resultados obtidos com a implantação da disciplina semipresencial e a iminente vontade da instituição em investir na forma bimodal de ensino, em outubro de 2007 foi aprovado no Conselho Universitário, por meio das Diretrizes Institucionais para Projetos Pedagógicos de Cursos de Graduação, anexo à Resolução 17/2007, a previsão de incluir, no mínimo, uma disciplina semipresencial na matriz curricular de todos os cursos de graduação reconhecidos na UPF. Tal iniciativa foi apontada como uma alternativa de flexibilização curricular que 
amplia as oportunidades de formação do estudante e torna o currículo menos rígido, capaz de absorver as mudanças nos diversos campos do conhecimento.

Diante disso, foi elaborado um Guia de Orientação para Disciplinas Semipresenciais, que procurou padronizar a oferta das mesmas em relação aos encontros e percentuais de aulas à distância. No guia foram propostos três modelos distintos a serem observados pelos cursos. Os modelos direcionam-se às disciplinas, de modo a respeitar a natureza das diferentes áreas do conhecimento que compõem a matriz curricular de cada curso. Enquadram-se, portanto, como as únicas opções possíveis de percentuais a serem adotados na instituição.

Cabe ressaltar que o colegiado do curso poderá optar por mais de um modelo na formatação de suas disciplinas semipresenciais, desde que tais atividades não ultrapassem os $20 \%$ da carga horária total para integralização curricular, conforme Portaria 4.059. Apresentam-se, na Tabela 2, os modelos propostos. Ressalta-se que o percentual de aulas sem presencialidade está condicionado:

- ao número de semanas previstas no calendário acadêmico para cada semestre letivo;

- ao número de créditos da disciplina a ser desenvolvida na forma bimodal;

- à obrigatoriedade da realização da primeira aula de forma presencial para apresentação do ambiente virtual de aprendizagem oficial;

- à obrigatoriedade da realização das avaliações da disciplina bimodal de forma presencial.

Tabela 2 - Modelos para disciplinas semipresenciais

\begin{tabular}{c|c|c}
\hline Modelo & Características & Percentual de aulas sem presencialidade \\
\hline A & Baixo índice de aulas não-presenciais & $20 \%$ \\
\hline B & Médio índice de aulas não-presenciais & $50 \%$ \\
\hline C & Alto índice de aulas não-presenciais & $80 \%$ \\
\hline
\end{tabular}

A Tabela 3 exemplifica a distribuição das aulas em uma disciplina semipresencial de quatro créditos (60 horas).

Tabela 3 - Exemplo de distribuição das aulas

\begin{tabular}{c|l}
\hline Modelo & \multicolumn{1}{c}{ Distribuição das aulas } \\
\hline A & $\begin{array}{l}\text { a) Cursos diurnos: três aulas não-presenciais distribuídas ao longo do semestre. } \\
\text { b) Cursos noturnos: quatro aulas não-presenciais distribuídas ao longo do semestre. }\end{array}$ \\
\hline B & Mesmo número de aulas presenciais e não-presenciais distribuídas ao longo do semestre. \\
\hline C & $\begin{array}{l}\text { a) Cursos diurnos: três aulas presenciais distribuídas ao longo do semestre. } \\
\text { b) Cursos noturnos: quatro aulas presenciais distribuídas ao longo do semestre. }\end{array}$ \\
\hline
\end{tabular}

Todas as definições pertinentes à organização didático-pedagógica da disciplina semipresencial devem estar devidamente previstas no plano de ensino, que inclui, dentre outros itens, o desenvolvimento metodológico, as estratégias e modalidades de avaliação e, especialmente, o cronograma, indicando as datas das aulas à distância. O plano de ensino é disponibilizado aos alunos no Ambiente de Apoio ao Aluno, ao início do semestre letivo, para que possa ser discutido e, se necessário, adaptado pelo professor. 


\section{Considerações Finais}

Conforme os dados apresentados neste artigo, a proposta da semipresencialidade, embora inicial, obteve resultados satisfatórios para alunos, para o professor e para a instituição.

O aperfeiçoamento desta modalidade nos cursos de graduação está vinculado à constante reflexão acerca de tal iniciativa e ao fortalecimento de uma cultura de EaD: $(i)$ na própria instituição; (ii) entre os docentes e (iii) entre os discentes.

Em busca da melhor preparação do corpo discente estão sendo oferecidos, sistematicamente, cursos de capacitação no ambiente virtual de aprendizagem institucionalizado. Desde a oferta da primeira disciplina semipresencial na instituição, quatro edições do curso já foram realizados, totalizando 100 alunos capacitados. Alguns professores já estão identificando pontos positivos nesse processo. Da mesma forma, são ofertados cursos de formação em EaD para os professores envolvidos com a modalidade semipresencial. Além disso, é realizado um acompanhamento constante destes professores, por meio de um grupo de estudos institucionalizado no segundo semestre de 2008 com o objetivo de auxiliar na preparação das aulas e verificar pontos positivos e negativos no andamento da disciplina.

A semipresencialidade é uma etapa que, entre outras funções, contribui para preparar a instituição, em todos os seus aspectos, para que a experiência efetiva de educação a distância aconteça com qualidade.

\section{Referências Bibliográficas}

Filatro, Andrea. Design instructional contextualizado - educação e tecnologia. São Paulo: Editora Senac São Paulo. 2007.

Maia, Carmem e Mattar, João. ABC da EaD. São Paulo: Pearson Prentice Hall. 2007. Moore, Michael e Kearsley, Greg. Educação a Distância - uma visão integrada. São Paulo: Thomson Learning. 2007.

SEED/MEC. Referenciais de Qualidade para Educação Superior a Distância Versão Preliminar. Brasília, 2007. 